\title{
On de Haan's Uniform Convergence Theorem
}

\author{
IVAN D. ARANĐELOVIĆ
}

\begin{abstract}
In [Univ. Beograd Publ. Elektrotehn. Fak. Ser. Math. 15 (2004), 85-86], we proved a new inequality for the Lebesgue measure and gave some applications. Here, we present as it new application new short and simple proof of de Haan's uniform convergence theorem.
\end{abstract}

A measurable function $g:(0,+\infty) \rightarrow(0,+\infty)$ is translational $\mathcal{O}$-regularly varying if

$$
\varlimsup_{s \rightarrow \infty} \frac{g(s+t)}{g(s)}<+\infty
$$

for each $t \in \mathbf{R}$. For properties and applications of this class of mappings see Tasković [5].

Let $\lambda$ be a Lebesgue measure on the set of real numbers $\mathbf{R}$. In [1] we present the following inequality, and as its applications short and simple proofs of two famous Steinhaus' results.

Proposition 1 (I. Aranđelović [1]). Let $A$ be a measurable set of a positive measure and $\left\{x_{n}\right\}$ a bounded sequence of real numbers. Then

$$
\lambda(A) \leq \lambda\left(\overline{\lim }\left(x_{n}+A\right)\right) .
$$

Now, as new application of Proposition 1, we present the following new short and simple proof of de Haan's uniform convergence theorem [4]. For applications of this result see [2],[3] or [4].

Proposition 2 (L. de Haan [4]). Let $f, g: \mathbf{R} \rightarrow \mathbf{R}$ be a measurable functions such that $g(s)>0$ for any $s, g$ is translational $\mathcal{O}$-regularly varying function and

$$
\lim _{s \rightarrow \infty} \frac{f(t+s)-f(s)}{g(s)}<+\infty
$$

for all $t \in \mathbf{R}$. Then

$$
\lim _{s \rightarrow \infty} \sup _{t \in[a, b]} \frac{f(t+s)-f(s)}{g(s)}<+\infty,
$$

for any $a, b \in \mathbf{R}$ such that $a<b$.

2000 Mathematics Subject Classification. Primary: 26A12; Secondary: 28A05.

Key words and phrases. inequality, Lebesgues measure, uniform convergence. 
Proof. By Egoroff's theorem follows that for any $a, b \in \mathbf{R}$ such that $a<b$, there exists measurable set $A \subseteq[a, b]$ such that $\lambda(A)>0$ and

$$
\lim _{s \rightarrow \infty} \sup _{t \in A} \frac{f(t+s)-f(s)}{g(s)}<+\infty .
$$

Assume now that convergence is not uniform on $[a, b]$. Then there exists $\left\{x_{n}\right\} \subseteq[a, b]$ and $\left\{y_{n}\right\} \subseteq \mathbf{R}$ such that $\lim y_{n}=\infty$ and

$$
\lim \frac{f\left(x_{n}+y_{n}\right)-f\left(y_{n}\right)}{g\left(y_{n}\right)}=\infty .
$$

By Proposition 1 follows that

$$
\lambda\left(\overline{\lim }\left(A-x_{n}\right)\right) \geq \lambda(A)>0,
$$

which implies that there exists $t \in \mathbf{R}$ and subsequence $\left\{x_{n_{j}}\right\} \subseteq\left\{x_{n}\right\}$ such that $\left\{t+x_{n_{j}}\right\} \subseteq A$. Then

$$
\begin{gathered}
\frac{\left|f\left(x_{n_{j}}+y_{n_{j}}\right)-f\left(y_{n_{j}}\right)\right|}{g\left(y_{n_{j}}\right)} \leq \\
\leq \frac{\left|f\left(x_{n_{j}}+t+y_{n_{j}}-t\right)-f\left(y_{n_{j}}-t\right)\right|}{g\left(y_{n_{j}}-t\right)} \cdot \frac{g\left(y_{n_{j}}-t\right)}{g\left(y_{n_{j}}\right)}+\frac{\left|f\left(y_{n_{j}}-t\right)-f\left(y_{n_{j}}\right)\right|}{g\left(y_{n_{j}}\right)} .
\end{gathered}
$$

Now

$$
\lim \frac{\left|f\left(x_{n_{j}}+t+y_{n_{j}}-t\right)-f\left(y_{n_{j}}-t\right)\right|}{g\left(y_{n_{j}}-t\right)}<+\infty,
$$

because $\left\{t+x_{n_{j}}\right\} \subseteq A$ and $\lim \left(y_{n_{j}}-t\right)=\infty$. From (1), (2) and

$$
\lim \frac{f\left(y_{n_{j}}-t\right)-f\left(y_{n_{j}}\right)}{g\left(y_{n_{j}}\right)}<+\infty
$$

follows

$$
\varlimsup \frac{f\left(x_{n_{j}}+y_{n_{j}}\right)-f\left(y_{n_{j}}\right)}{g\left(y_{n_{j}}\right)}<+\infty,
$$

which is a contradiction.

\section{REFERENCES}

[1] I. D. Aranđelović, An inequality for the Lebesgue measure, Univ. Beog. Publ. Elek. Fak. ser. Math. 15 (2004) 85-86.

[2] N. H. Bingham, C. M. Goldie and J. L. Teugels, Regular Variation, Cambridge Univ. Press 1987.

[3] J. L. Geluk and L. de Haan, Regular variation, extensions and Tauberian theorems, CWI Tract 40, Amsterdam 1987. 
[4] L. de Haan, On Regular Variation and its Applications to the Weak Convergence of Sample Extremes, Math. Centre Tract, No. 32, Amsterdam 1970.

[5] M. R. Tasković, Fundamental facts on translational $\mathcal{O}$-regularly varying functions, Mathematica Moravica, Vol. 7 (2003), 107-152.

IVAN ARANĐELOVIĆ

Faculty of Mechanical Engineering

UNIVERSity OF BELGRADE

Kraljice MariJe 16

11000 BEOGRAD

Serbia

E-mail address: iarandjelovic@mas.bg.ac.rs 